\title{
Epithelioid haemangioendothelioma of the scapula in a child: A case report and review of the literature
}

\author{
Dr MN Rasool MBChB, FCS Orth(SA), PhD(UKZN) \\ Consultant Orthopaedic Surgeon \\ Dr RF Snyders MBChB \\ Registrar Orthopaedics \\ Dr G Bydawell MBChB, FRCR (SA) \\ Consultant Radiologist \\ Corresponding author: \\ Dr MN Rasool \\ Department of Orthopaedic Surgery \\ University of Kwa-Zulu Natal \\ Nelson R Mandela School of Medicine \\ Private Bag 7 \\ Congella, Durban, 4001 \\ Tel: 0312604297 \\ Email: rasool@ukzn.ac.za
}

\begin{abstract}
Epithelioid haemangioendothelioma (EHE) is a vascular tumour which rarely affects bone. A 10-year-old girl presented with slow onset of swelling of the scapula for 6 months. Radiology revealed a destructive lesion of the scapula. Histology confirmed epithelioid haemangioendothelioma. Pre-operative transarterial embolisation was performed to decrease the vascularity of the tumour. The tumour was completely resected with the entire scapula. Post-operatively the child improved with useful function and a stable shoulder 13 months later. Large, isolated EHE of the scapula has not been reported in children.
\end{abstract}

Key words: epithelioid haemangioendothelioma, scapula, transarterial embolisation, scapulectomy

\section{Introduction}

Epithelioid haemangioendothelioma (EHE), a rare tumour of vascular endothelial origin, is one of the lesser-known tumours of bone. The tumour pursues a clinical course between that of a haemangioma and an angiosarcoma. It occurs mainly in soft tissues such as the skin, liver and lung, but rarely in bone. The osseous lesions may be solitary but the majority are multi-centric. ${ }^{1-5}$ The lower limbs are more commonly involved. The scapula is a very rare site of involvement and this tumour is uncommon in children. One report only, occurring in the scapula, has been described in a child as part of a multi-centric involvement. ${ }^{6} \mathrm{EHE}$ can be misdiagnosed as a metastatic carcinoma or primary sarcoma in children. Resection is still the primary modality of treatment. Radiotherapy is useful for surgically inaccessible sites. Profuse local bleeding at the time of biopsy or surgery has been reported., ${ }^{4,8}$
The aim of this report is to describe a rare site of involvement of EHE in the scapula, and the value of preoperative transarterial embolisation (TAE) to decrease operative bleeding during scapulectomy.

\section{Case report}

A 10-year-old girl was referred from a rural hospital for a slow-growing, enlarging mass, associated with pain over the right scapula. Symptoms were present for 6 months. An open biopsy was done in the rural hospital. The report of the biopsy, which was done at the referral hospital, was inconclusive. The child was well, but slightly pale. The swelling was $20 \mathrm{~cm} \times 15 \mathrm{~cm} \times 12 \mathrm{~cm}$ fixed to the scapula and involving the supra- and infraspinous fossae (Figure 1). The skin was adherent to the tumour over the biopsy site only. Multiple dilated veins were present. Axillary and supraclavicular lymph nodes were not enlarged. 


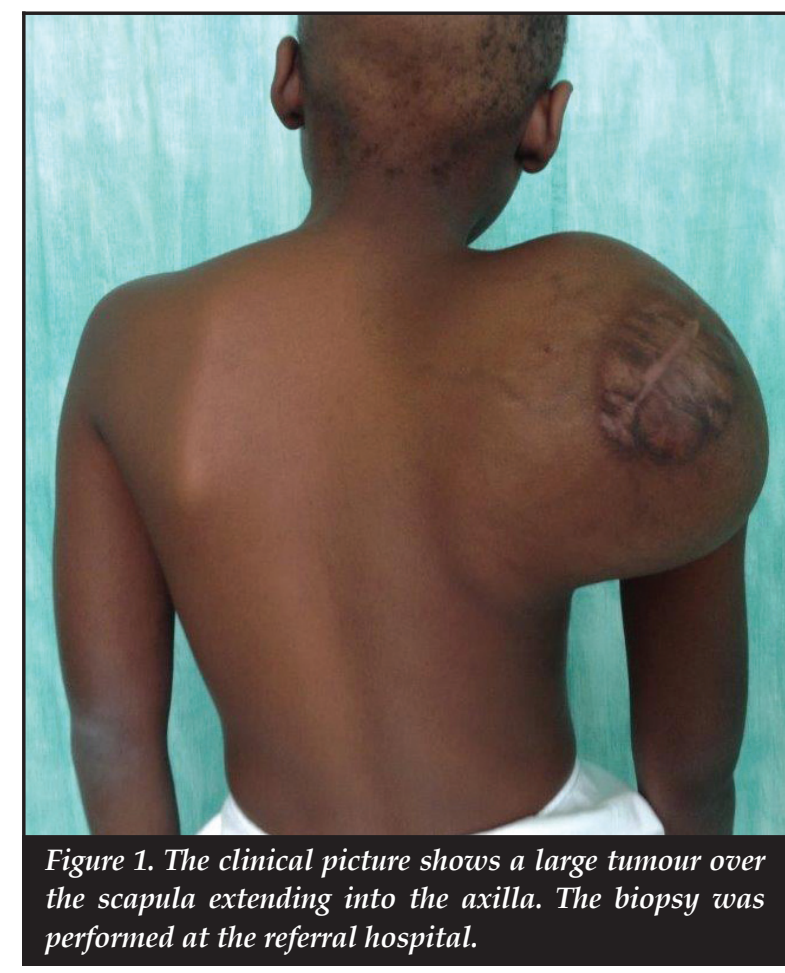

All shoulder movements were limited. There was no neurovascular involvement. The elbow and the hand function were good, though the arm muscles were wasted.

Plain radiographs of the right scapula showed a large tumour with destructive changes (Figure 2). MRI showed a multi-lobulated mass of heterogeneous signal intensity, with central necrosis but no calcification (Figure 3). The neurovascular bundle was displaced anteriorly. There was no infiltration of the chest wall. A pathological fracture of the glenoid neck was present.

The haemoglobin was $8 \mathrm{~g} / \mathrm{L}$ and the ESR was $15 \mathrm{~mm} / \mathrm{hr}$. Staging investigations revealed that the lesion was confined to the scapula, with the bone scan showing no other areas of increased uptake. The tru-cut biopsy revealed haemangioendothelioma of bone on histology.

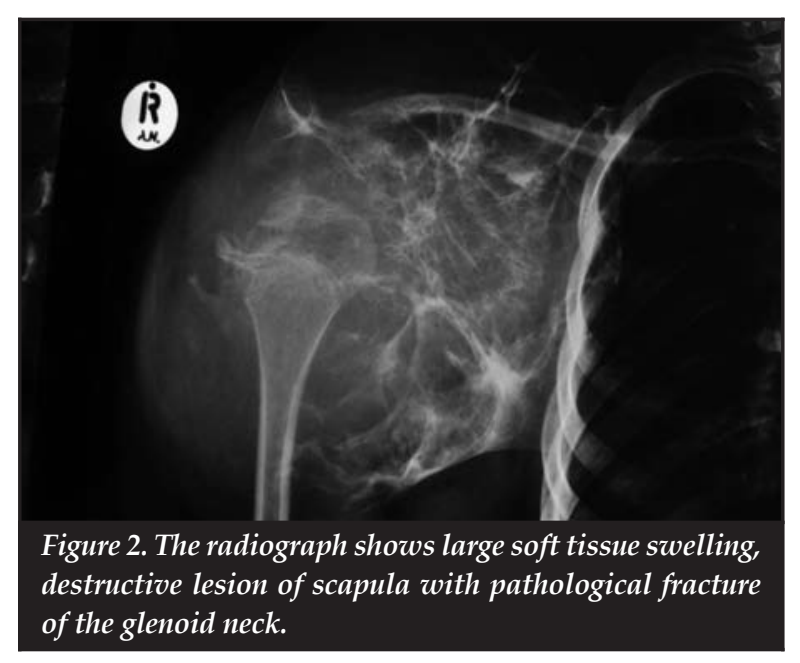

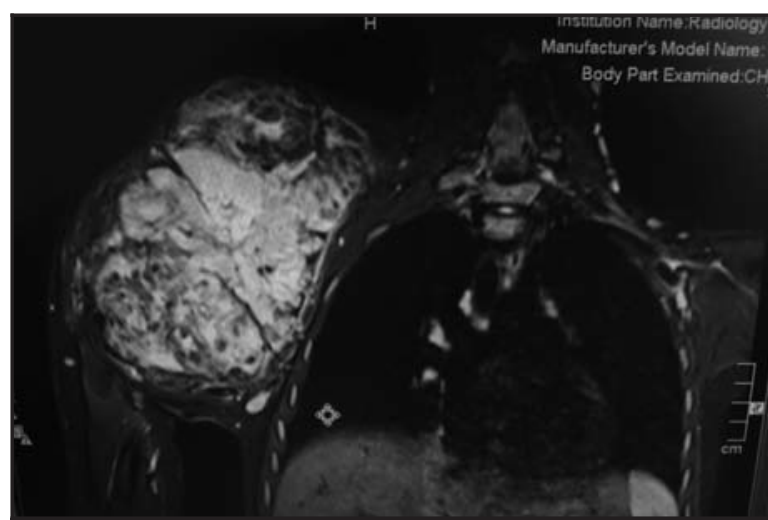

Figure 3. The MRI scan shows large multilobulated tumour of heterogeneous signal intensity.

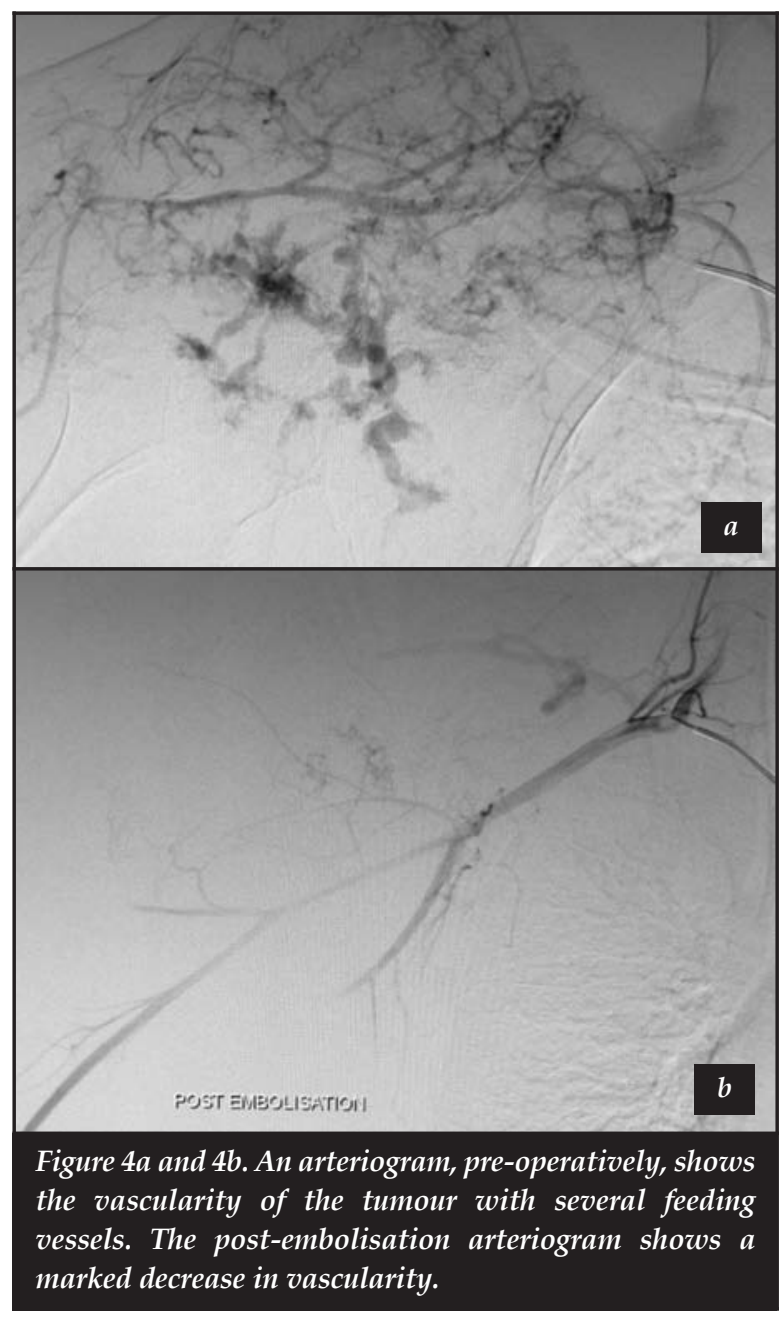

Using 300-500 and 500-700 micron particles, a transarterial embolisation was performed by an interventional radiologist. The tumour-feeding branches from the axillary artery was targeted, using a micro-catheter. This allowed a window period in which to surgically remove the tumour (Figures $4 a$ and $4 b$ ). 
A tumour resection was performed 6 days after the embolisation. The previous biopsy scar was excised and the incision was extended to the inferior angle of the scapula, and supero-laterally to the axilla. From inferomedially, the latissimus dorsi, rhomboids, levator scapulae and the trapezius were divided. The tumour was removed dividing the serratus anterior, reflecting the posterior deltoid from the acromion and dividing the rotator cuff. The lateral $2 \mathrm{~cm}$ of the acromion, together with the clavicle, remained after the resection of the entire scapula. The acromion was anchored posteriorly to the third rib with sutures to prevent drooping. Bleeding was noted to be mild to moderate and the wound was closed over a suction drain. The tumour weighed $1.3 \mathrm{~kg}$.

Histology confirmed a low grade EHE of bone with no signs of mitosis. The tumour was non-encapsulated and the soft tissue margin was free from tumour.

Post-operatively the child made good progress and was immobilised in a broad arm sling for 4 weeks. There were no neurovascular problems. At 13 months followup, the child gained weight, shoulder flexion and extension were $30^{\circ}$ each, internal rotation was $40^{\circ}$ and external rotation $15^{\circ}$, abduction reached $20^{\circ}$, and passively the limb could be elevated to above the head (Figure 5). There was no recurrence, pain or instability of the joint (Figure 6).

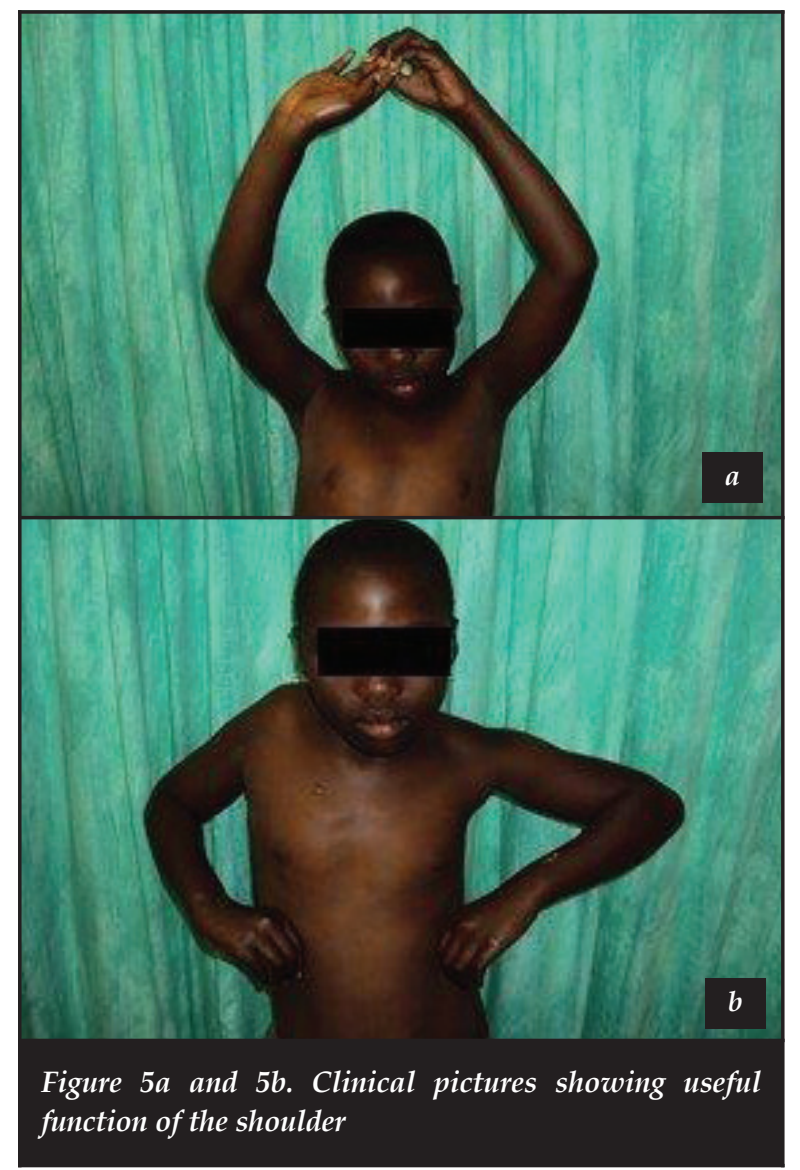

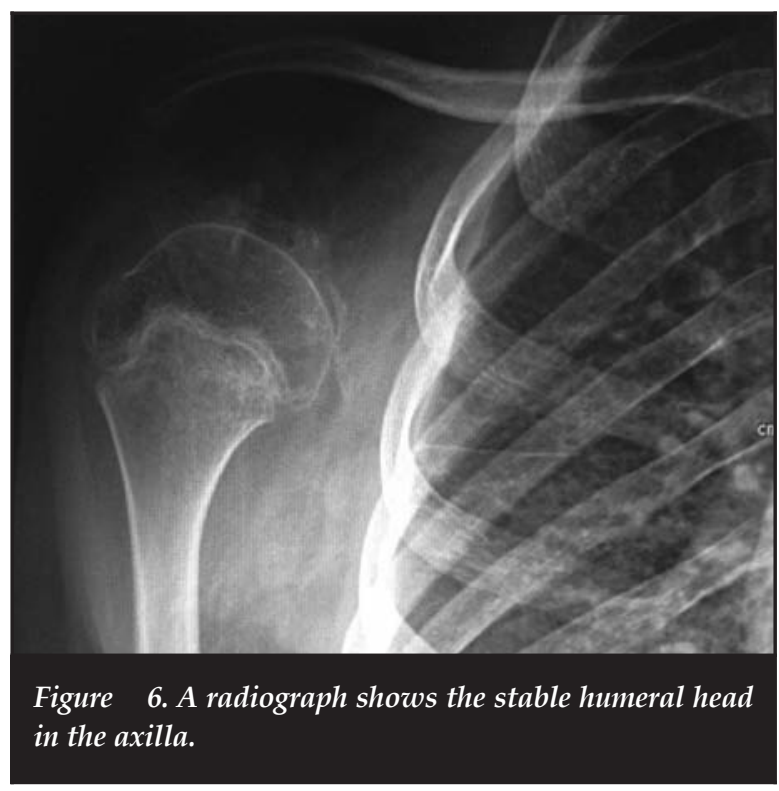

Histology confirmed a low grade EHE of bone with no signs of mitosis. The tumour was non-encapsulated and the soft tissue margin was free from tumour

\section{Discussion}

$\mathrm{EHE}$ of bone is rare. The incidence is between $0.1 \%$ to $1 \%$ of all malignant primary bone tumours. This tumour is usually seen in soft tissues such as the liver and lungs. Bone lesions are usually multi-centric and have a predilection for long bones of the extremities, usually the lower limbs. Lesions are often located in the diaphysis, but may occur in the metaphysis or meta-epiphysis. Less frequently, this tumour is found in the vertebral column, the upper limbs, and flat bones..$^{1-5,7,9,10}$

The age distribution ranges from 10-73 years (mean 30 years).

EHE comprises two general groups, those of low grade malignancy, and those that are highly malignant and metastatic. ${ }^{4,7}, 8$

Clinically the tumour is slow growing, and the time from initial symptoms to presentation is reported as 7 months to 8 years. ${ }^{1}$ Pathological fractures may be the presenting problem, but the major clinical manifestations of EHE of bone are pain and swelling. Microangiopathic haemolytic anaemia, consumption coagulopathy and high output cardiac failure due to arterio-venous shunts have been reported. ${ }^{9,11}$

Radiologically the lesions are osteolytic, expansile and multi-focal. Reactive new bone formation is rare. The lesions may be in cancellous or cortical bone. Occasionally, the radiological appearance is 'honeycombed' or may have 'ballooning' features with bulging of the thinned cortex..$^{4-8}$ Calcification is occasionally seen in large, deeply situated tumours. ${ }^{6}$ 
Macroscopically the appearance of the tumour tissue is dark red or brownish. The consistency is soft but it may be firm if the cells are in dense collagen fibres. Profuse bleeding may be encountered during surgery. ${ }^{48,9}$

Microscopically, a rich network of anastomosing vessels, lined with atypical epithelial cells are seen, together with primitive vaso-formative features, and vascular channels showing various stages of angiogenesis. Silver staining of the vascular reticulin sheath is useful in distinguishing EHE from haemangiopericytoma and other vascular tumours. ${ }^{5,7}$ Deposits of haemosiderin may be noted.

Ultra-structurally the important feature is the presence of the vascular lumina showing various degrees of maturation. The endothelial nature of the tumour can be confirmed by the presence of Weibel-Palade bodies and Factor VIII related antigen in the vascular endothelial cells. ${ }^{5-7}$ Tumours are graded I-III, though histological grading can be difficult in Gr II and Gr III, and in the case of recurrence. ${ }^{4,5}$ High and low malignant areas may be present initially in the same tumour. ${ }^{5}$ The most important criterion for predicting the prognosis of EHE of the bone was visceral involvement. ${ }^{4,5}$

When metastasis occurs, it usually develops from the tumours with atypical features. Mitosis ( $>1$ per HP field), focal spindling or cell necrosis are features of a more aggressive course. Metastases in regional nodes may occur in 30\%. The overall survival for solitary EHE is $89 \%$ and $50 \%$ for those with multi-focal disease.

EHE can be misdiagnosed as metastatic carcinoma, due to its growth pattern and low mitotic activity. In children, Ewing's sarcoma, rhabdomyosarcoma, osteolytic osteosarcoma and skeletal angiomatosis must also be

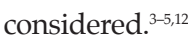

In accessible regions, radical excision is the treatment of choice. ${ }^{47}$ Radiation treatment alone may be effective in some patients with multi-centric tumours. The potential for complications must be considered. The role of chemotherapy is not clear but it may be used to treat tumours involving multiple bones.

Limb-sparing resection of the scapula is rarely done in children. In an adult with sarcoma, Villalobos et al..$^{13}$ performed a resection of the scapula and reconstruction using a customised scapula endoprosthesis. This is a useful alternative to forequarter amputation. The result was satisfactory with good elbow and hand function, though overhead activity was limited. The child in this report was able to perform activities of daily living with limitation of overhead activities. Cosmetically the outcome was more acceptable, and functionally superior to a forequarter amputation.
Trans-arterial embolisation (TAE) is one of the more important treatment modalities being used in the treatment of primary and secondary bone tumours. ${ }^{14-16} \mathrm{It}$ reduces vascularity and intra-operative blood loss thereby allowing for better definition of tissue planes, and assisting in complete excision during surgery. The principles of TAE of bone tumours are the precise targeting of the occlusive embolic material to the tumour-feeding vessels. The aim is the occlusion of the tumour capillary bed, and not the major arterial feeders. Embolic agents used are either liquid or particulate. Occluding only the major vessels leads to vascularisation of the tumour via other vessels. Tumour types treated include metastatic lesions, giant cell tumours, aneurysmal bone cysts, vertebral haemangiomas, osteosarcomas and arterio-venous malformations. ${ }^{16}$ Lower operative blood loss and the decreased need for intra-operative transfusion were advantages in the excision of the tumour in this patient.

In conclusion, EHE is rare in children. Only one scapula lesion has been described in a child, as part of a multi-centric involvement. ${ }^{6}$ Primary solitary scapula lesions have only been described in adults. ${ }^{4,13}$ The child in this study had a large primary tumour isolated to the scapula. The morbidity of a forequarter amputation was avoided and the child has useful upper limb function.

No benefits of any form have been or are to be received from a commercial party related directly or indirectly to the subject of the article.

\section{References}

1. Weiss SW, Ishak KG, Dail DH, Sweet DE, Enzinger FM. Epithelioid hemangioendothelioma and related lesions. Semin Diagn Pathol 1986;3:259-87.

2. Stout AP. Hemangio-endothelioma: a tumor of blood vessels featuring vascular endothelial cells. Ann Surg 1943;118:445-64.

3. Weiss SW, Goldblum JR Epithelioid Haemangioendothelioma: Vascular tumours of Intermediate malignancy. Enzinger and Weiss. Soft Tissue Tumors $5^{\text {th }}$ Edition: 2008 Chapter 23, pp 681-88. Mosby Elsevier.

4. Kleer CC, Unni KK, Mcleod RA. Epithelioid hemangioendothelioma of bone. Am J Surg Pathol 1996;20:130111.

5. Campanacci M, Boriani S, Giunti A. Hemangioendothelioma of bone: a study of 29 cases. Cancer 1980;46:804-14.

6. Tsuneyoshi M, Dorfman HD, Bauer TW. Epithelioid hemangioendothelioma of bone: a clinicopathologic, ultrastructural, and immunohistochemical study. Am J Surg Pathol 1986;10:754-64.

7. Garcia-Moral CA. Malignant hemangioendothelioma of bone. Review of world literature and report of two cases. Clin Orthop 1972;82:70-79. 
8. Bundens WD, Brighton CT. Malignant hemangioendothelioma of bone: report of two cases and review of the literature. J Bone Joint Surg (Am)1965;47-A:762-72.

9. Srinivasan CK, Patel MR, Pearlman HS, Silver JW. Malignant hemangioendothelioma of bone: Review of the literature and report of two cases. J Bone Joint Surg (Am)1978;60-A:696-700.

10. Sweterlitsch PR, Torg JS, Watts H. Malignant hemangioendothelioma of the cervical spine. A case report. Bone Joint Surg (Am)1970;52-A:805-808.

11. Lye DJ. Wepfer JF, Haskell DS. Low grade hemangioendothelioma of the clavicle and acromion. Case report 458, Skeletal Radiology 1988;17:57-59.

12. Volpe R, Mazabraud A. Hemangioendothelioma (angiosarcoma) of bone: a distinct pathologic entity with an unpredictable course. Cancer 1982;49:727-36.

13. Villalobos CE, Hayden BL, Silverman A, Choi I, Wittig JC. Limb-sparing resection of the scapula and reconstruction with a constrained total scapula prosthesis: A case of multicentric epithelioid hemangioendothelioma involving the scapula and surrounding soft tissues. Ann Surg Oncol 2009;16:2321-22.
14. Gupta P, Gamanagatti S. Preoperative transarterial Embolization in bone tumors. World J Radiol 2012;4:18692.

15. Ibrahim WH, Safran ZA, Hasan H, Zeid WA. Preoperative and therapeutic embolization of extremities of bone and soft tissue tumors. Angiology 2013;64:151-56.

16. Owen RJ. Embolization of musculoskeletal bone tumors. Semin Intervent Radiol 2010;27:111-23.

This article is also available online on the SAOA website (www.saoa.org.za) and the SciELO website (www.scielo.org.za). Follow the directions on the Contents page of this journal to access it. 